\title{
Antenatal Education on Childbirth Self-Efficacy for Egyptian Primiparous Women: A Randomized Control Trial
}

\author{
*Rania El-Kurdy ${ }^{1,}$ Samia I Hassan ${ }^{2,}$ Nahed Fikry Hassan ${ }^{3,}$ Amina El-Nemer ${ }^{4}$ \\ ${ }^{1}$ Assistant Lecturer of Woman Health and Midwifery Nursing Dep. Faculty of Nursing, Mansoura University, \\ Egypt. \\ ${ }^{2}$ Lecturer of Woman Health and Midwifery Nursing Dep. Faculty of Nursing, Mansoura University, Egypt. \\ ${ }^{3}$ Assistant Professor of Woman Health and Midwifery Nursing Dep. Faculty of Nursing, Mansoura University, \\ Egypt. \\ ${ }^{4}$ Professor of Woman Health and Midwifery Nursing Dep. Faculty of Nursing, Mansoura University, Egypt. \\ Corresponding Author: Rania El-Kurdy
}

\begin{abstract}
Antenatal education is provided as a standard guideline in developed countries but till now, there is no standard program in developing countries. This study aimed to test the application of antenatal education on childbirth self-efficacy for Egyptian primiparous women. Subjects and methods: A randomized Control Trial was utilized comparing two groups of women an antenatal education group $(n=52)$ and a routine antenatal care control group (n=52). The study was carried out at Antenatal Clinic at Mansoura New General Hospital, Mansoura city, Egypt between November 2015 and August 2016. Results: Women who attended antenatal education classes had a greater childbirth self-efficacy and a lower perceived labour pain $(p=<0.001)$. Conclusion: Antenatal educational classes give an actual chance for helping primiparous women increasing childbirth self-efficacy, and reducing labour pain in the first and second stages. The study recommended the importance of designing and applying antenatal education classes as an essential component of standard antenatal care at different affiliated Egyptian public hospitals. Designing and applying childbirth preparation classes in the third trimester of pregnancy particularly for primigravidas. Designing comprehensive updated booklet of childbirth preparation which is suited and tailored to the culture of the Egyptian women and distributed through private and different affiliated Egyptians antenatal clinics. Finally immediate strategies should be adopted to move from medicalization of childbirth to humanistic and low intervention midwife-led care which is empowering Egyptians women.
\end{abstract}

Keywords: Antenatal education, Antenatal Standard, Childbirth preparation, Childbirth Self-Efficacy, Pregnancy training classes.

Date of Submission: 04-07-2017

Date of acceptance: 17-07-2017

\section{Introduction}

Pregnancy and childbirth are a long time journey and it is accompanying with physiological, psychological and emotional changes which may cause positive or negative effect on the woman's life, the baby, and the family $[1,2]$. A birth of a healthy newborn is the crucial goal of any pregnancy, to achieve this goal the nurses play a significant role in helping the pregnant woman, her husband, and her family [3]. The series of obstacles may face the pregnant woman includes; misunderstanding, questions without answers and inadequate giving information about pregnancy and childbirth, all those are common and too serious affecting woman's health [4]. The nurse should solve these obstacles and gives support to the woman during these transitional critical processes. The pregnant woman should obtain the ideal standardized care from nurses who recognize the aims of antenatal and intranatal care [5].

Antenatal education is an instrument which helps future mothers, to take safe decisions before birth and during birth, to utilize skills for self-control of labour pain, to utilize skills for postnatal care, infant care, breastfeeding and motherhood [6,7]. Despite the fact that antenatal education has a great position in promoting normal childbirth [8]. A systematic review in the Cochrane library found that the effects of antenatal education and birth preparation are still largely unknown and controversial exists about its importance [9]. The antenatal education is provided as a standard guideline in developed countries; but till now, there is no standard program in developing countries [10]. The pain of childbirth is the most fearful feeling especially for the first time mother. The level of childbirth fear is higher in primiparous women than in multiparous women $[11,12]$. The reason for that is the lack of self-confidence, the expectation of intolerable pain, negative stories of another women, inadequate physical and psychological feeling for birth, loss of self-control, fear from perineal laceration, lack of support from the birth team, and fear of death [13, 14]. The goal of childbirth care is reaching a healthy mother and baby, and to get a positive childbirth experience. Failure to get high quality care for 
woman and her baby during childbirth process, particularly in her first labour, may put permanent emotional and physical scars which may cause a refusal of the care offers. In other words, push the woman to prefer caesarean section (CS) in the next pregnancy or having no more children [3].

\subsection{Significant of the study:}

Antenatal care (ANC) guidelines will be effective and with a positive pregnancy experience; if it is integrated to provide relevant, clear, and appropriate information. The pregnant women must have all information about the labour and delivery process before the $36^{\text {th }}$ weeks of gestation with the emphasis on the use of a birth plan, childbirth preparation, the onset of labour, and pain relief measures $[15,16]$.

Antenatal education is not applied in Egyptian health care systems. Therefore, pregnant women fell under the threats of inadequate information, negative attitude toward natural childbirth and fear from childbirth which lead to requested CS without medical indications [17, 18]. According to MOHP (2015) the rate of CS increased in Egypt from (28\%) in 2008 to (52\%) in 2014. Regarding Dakahlia Governorate the rate of CS was $(65.5 \%)$ in 2014 [19]. Antenatal education with adequate information required for reaching the right decision helps those pregnant women to go back to nature and give birth normally with better satisfaction with their childbirth experiences $[18,20,21]$.

\section{Subjects and Methods}

2.1 Study aim: This study aims to test the application of antenatal education on childbirth self-efficacy for Egyptian primiparous women

\subsection{Study hypothesis:}

- H1. Women who will receive antenatal education will have higher level of childbirth self-efficacy than those in the control group.

- H2. Women who will receive antenatal education will experience less level of labour pain than those in the control group.

2.3 Study design: A randomized Control Trial was carried out between November 2015 and August 2016.

\subsection{Study setting and participants:}

The study was conducted in the Antenatal Clinic at Mansoura New General Hospital, Mansoura city, Dakahlia governorate, Egypt. Dakahlia governorate is located in the North Eastern Region of Delta, Egypt. Mansoura is called the capital of medicine in Egypt.

Mansoura New General Hospital is a public hospital provides free services to women during pregnancy, labour, and postpartum. The Antenatal Clinic is opened daily from Saturday to Thursday, from 9 am to $2 \mathrm{pm}$. The care was provided by two nurses and five obstetricians (consultant, specialist assistant, specialist, and two juniors). There are between 75-100 follow up cases weekly and 5-10 new cases each day. The routine ANC visit takes from 5-10 minutes, it is consisted of collecting complete history taking, a physical examination and ultrasonography. No antenatal education is offered for pregnant women in these visits, as antenatal educational classes are currently not a part of routine ANC.

Participants who were fulfilled the following inclusion criteria were randomly selected to be included in the study: Primigravida who: Aged from 20 to 35 years old, was at their $32^{\text {nd }}$ to $34^{\text {th }}$ weeks of gestation, attended for ANC in Mansoura New General Hospital, had a singleton vaginal delivery, had no medical or psychological problem, was able to read and write, and Agreed to give a written informed consent.

\subsection{Sampling:}

The sample size was determined using the following formula at 5\% level of significance and $80 \%$ power: $\mathrm{N}=(\mathrm{Z} 1-\alpha / 2+\mathrm{Z} 1-\beta)^{2} \sigma 1 \sigma 2 / \delta^{2}$. For this study, a sample size was 104 women 52 in each group. The antenatal education group were attended the antenatal education classes and control group were received routine ANC only. Fig. 1 shows the flow chart for the study phases.

2.6 Data collection: To achieve the study aim the following three tools were used:

\section{Tool 1: Interview questionnaire:}

It was designed to collect personal data for recruiting women before the implementation. It consisted of women socio-demographic data such as; age, place of residence, religion, educational level, and occupation.

Tool 2: Childbirth Self-Efficacy Inventory (CBSEI):

It is adopted from (Lowe, 1993) [22]. It is a self-report measuring the outcome expectancy (OE) and selfefficacy expectancy (EE) for labour and birth. This questionnaire was composed of 62 items and divided into four subscales categorized in two parts: 
- Part One: - measures two subscales (OE-15 items \& EE-15 items) during the first stage of labour when contractions are not more than five minutes apart.

- Part Two: - measures two subscales (OE-16 items \& EE-16 items) in the second stage of labour during the push the baby out to give birth. For each subscale, the participants rank their feelings about the listed behaviours on Likert 10 level scale, ranging from $1=$ not at all helpful to $10=$ very helpful for the OE subscales and $1=$ not at all sure to $10=$ very sure for the EE subscales. The two subscales of active labour (AL) includes 15 items thus the total score was from 0 to 150. The two subscales of the second-stage (SS) includes 16 items thus the total score was from 0 to 160. A total childbirth OE score includes the outcome AL plus the outcome SS scale scores. A total childbirth EE score includes the efficacy-AL plus the efficacy-SS scores. The overall score for each part includes (the outcome expectancies and the self-efficacy expectancies) which extends from 31 to 310.

\section{Tool 3: Numerical Rating Scale (NRS):}

It is adopted from (Breivik et al., 2008 \& Jones, Vojir, Hutt \& Fink 2007) [23, 24]. It was offered to women during pain to rate their pain score. In the NRS, the women had the option to verbally rate their scale from 0 to 10 or put a dot on a line indicating their level of pain. Score 0 indicates no pain, while score 10 represented the most intense pain. The score distance between 1 and 3 is a mild pain while score between 4 and 6 indicated moderate pain and between 7 and 10 score indicated sever pain. This tool was used during the first and second stages of childbirth.

\subsection{Pilot study}

Pilot study was conducted on 10 women to assess the tools used, to estimate the time needed to complete each tool, as well as to evaluate the settings of the study. According to the analysis of the pilot study the time required of the CBSEI questionnaire was 10 minutes.

\subsection{Field work}

During the study period the researcher attended the study setting and checked the registered book to identify the pregnant women who meet the inclusion criteria. The researcher met each woman separately, a full explanation of the aim and the scope of the study was given to retrieve women acceptance and their written consent. The complete instructions about the tools of data collection were given. Tool one interview questionnaire and tool two the CBSEI were used for recruitment in the study as initial baseline assessment. The researcher was randomly assigned the participants to antenatal education and control group upon completing the baseline assessment. The control group received the routine ANC and exposed to all conditions of the antenatal education group except for antenatal education sessions. The researcher divided the participants in the antenatal education group into small groups, the size of the group is 10 women to allow for individual attention, participation and sharing experiences. They were offered a structured antenatal education classes which is consisting of 270 hours of instruction. It splitted into three 90-minute weekly sessions. The content of educational classes are presented in Table 5. The content and structure of antenatal education classes were guided by Dick-Read's "natural labour", Lamaze's"psychoprophylaxis and Mongan's "hypnobirthing" philosophy [25, 26, 27] and tailored to be culturally relevant to the needs of Egyptians women and congruent with the local Egyptian hospital culture. The sessions of antenatal education classes were conducted using; posters, slide power point presentations, animation videos, and demonstration. The CBSEI (posttest) was collected again at the end of the third class, also data were collected from the control group at the same period during a scheduled ANC visit. After conducting the 3 sessions with women in the antenatal education group, the researcher went back to the labour and delivery unit after knowing the time and place of labour by the participants contacting. The researcher attended with all participants (antenatal education and control groups) during labour and delivery, to evaluate labour pain by using the NRS, and evaluate women's childbirth selfefficacy by using the CBSEI.

\subsection{Ethical approval}

- Informed written consents were retrieved from women's participated in the study and they assured about their rights to withdraw from the study at any time.

- Data collection tools did not touch women's religious, cultural, ethical aspects and did not harm women's reproductive health.

- All ethical issues were considered in dealing with the collected data

\subsection{Data analysis}

The statistical analysis was done by using SPSS version 22. Qualitative data were described using frequencies and percentage. Association between categorical variables was tested using Chi-square test $\left(x^{2}\right)$. When more than $25 \%$ of the cells have expected count less than 5, Fisher exact test was used. Continuous variables were presented as Mean \pm SD (standard deviation). The two paired groups were compared with Paired sample t test. The two unpaired (un matched groups were compared with Independent sample t test. Pearson correlation used for correlation between continuous parametric data.

\begin{tabular}{lll}
\hline DOI: $10.9790 / 1959-0604021523$ & www.iosrjournals.org & $17 \mid$ Page
\end{tabular}




\section{Results}

Table one presents socio-demographic characteristics of 104 pregnant women divided into two groups (antenatal education and control). Women's mean age in the antenatal education and control groups was respectively (26.92 $\pm 3.44 \& 26.36 \pm 3.74)$. Regarding to place of residence, more than two thirds of antenatal education group $(67.3 \%)$ and $(63.5 \%)$ of control group were from rural. Concerning the educational level, $(59.6 \%)$ of antenatal education group and less than half $(48.1 \%)$ of control group completed a university education. In relation to occupation, more than three quarters of antenatal education group (76.9\%) and the majority of control group (90.4\%) were housewives while, (23.1\% \& 9.6\% respectively) in the antenatal education and control groups were employed. There were no significant differences among both studied groups regarding socio-demographic characteristics.

Table two reveals mean of outcome expectancy and self-efficacy expectancy scores obtained by the study groups at pretest, posttest, and follow-up assessment. Regarding to the pretest there were no significant differences between the antenatal education and control groups in the mean of outcome expectancy and selfefficacy expectancy scores. But there were highly significant differences between the two groups at posttest and during follow-up assessment $(\mathrm{p}=<0.001)$. Clearly, the table shows the mean of outcome expectancy and self efficacy expectancy scores were higher in the antenatal education group.

Table three clarifies the mean score of labour pain during the $1^{\text {st }}$ stage among women in the antenatal education and control groups respectively $(5.08 \pm 0.68 \& 7.40 \pm 0.5)$. Also, the mean score of labour pain in the $2^{\text {nd }}$ stage among women in the antenatal education and control groups were respectively $(6.52 \pm 0.5 \& 8.56 \pm$ $0.7)$. The table highlighted that there were highly significant differences between the two groups regarding the mean score of labour pain at the $1^{\text {st }}$ and $2^{\text {nd }}$ stages of labour $(\mathrm{p}=<0.001)$.

Table four describes correlations between CBSEI subscales (outcome and self-efficacy expectancies) and labour pain score in the antenatal education group at pretest, posttest, and follow-up assessment. Regarding the pretest there were no significant correlation between CBSEI subscales and labour pain score during both the $1^{\text {st }}$ and $2^{\text {nd }}$ stages of labour. While, at posttest and follow-up assessment there were significant negative correlation between CBSEI subscales and labour pain score during both stages. Apparently, the table presents significant negative correlation between outcome expectancy and labour pain score during both the $1^{\text {st }}$ and $2^{\text {nd }}$ stages of labour $(\mathrm{p}=<0.001)$ also, between self-efficacy expectancy and labour pain score during both stages ( $\mathrm{p}$ $=0.016 \& 0.024$ respectively). As regards to follow-up assessment the table presents significant negative correlation between outcome expectancy and labour pain score during both the $1^{\text {st }}$ and $2^{\text {nd }}$ stages of labour $(\mathrm{p}=$ $<0.001 \& 0.042$ respectively) also, between self-efficacy expectancy and labour pain score during both stages (p $=0.006 \& 0.022$ respectively). According to table five, there were no significant correlation between CBSEI subscales (outcome and self-efficacy expectancies) and labour pain score at pretest. Concerning posttest there were no significant correlation between outcome expectancy and labour pain score during both the $1^{\text {st }}$ and $2^{\text {nd }}$ stages of labour ( $\mathrm{p}=0.73 \& 0.339$ respectively) also, between self-efficacy expectancy and labour pain score during both stages $(\mathrm{p}=0.084 \& 0.316$ respectively). Regarding follow up assessment, the table presents again there were no significant correlation between outcome expectancy and labour pain score during both the $1^{\text {st }}$ and $2^{\text {nd }}$ stages of labour ( $p=0.427 \& 0.812$ respectively) also, between self-efficacy expectancy and labour pain score during both stages ( $\mathrm{p}=0.08 \& 0.332$ respectively).

Table1. Socio-demographic characteristics of pregnant women in the study groups

\begin{tabular}{|c|c|c|c|c|c|c|}
\hline \multirow{2}{*}{$\begin{array}{l}\text { Socio-Demographic } \\
\text { Characteristics }\end{array}$} & \multicolumn{2}{|c|}{$\begin{array}{c}\text { Antenatal Education } \\
\text { Group }(\mathrm{n}=52)\end{array}$} & \multicolumn{2}{|c|}{$\begin{array}{c}\begin{array}{c}\text { Control Group } \\
(\mathrm{n}=52)\end{array} \\
\end{array}$} & \multicolumn{2}{|c|}{$\begin{array}{c}\text { Test of } \\
\text { Significance }\end{array}$} \\
\hline & \multicolumn{2}{|c|}{ Mean \pm SD } & \multicolumn{2}{|c|}{ Mean \pm SD } & t-test & p-value \\
\hline Age & \multicolumn{2}{|c|}{$26.92 \pm 3.44$} & \multicolumn{2}{|c|}{$26.36 \pm 3.74$} & 0.819 & 0.415 \\
\hline & $\mathbf{N}$ & $\%$ & $\mathbf{N}$ & $\%$ & $\mathbf{X}^{2}$ & p-value \\
\hline \multicolumn{7}{|l|}{ Place of Residence } \\
\hline Urban & 17 & 32.7 & 19 & 36.5 & \multirow{2}{*}{ 0.170* } & \multirow{2}{*}{0.837} \\
\hline Rural & 35 & 67.3 & 33 & 63.5 & & \\
\hline \multicolumn{7}{|l|}{ Religion } \\
\hline Moslem & 49 & 94.2 & 52 & 100 & \multirow{2}{*}{ 3.089* } & \multirow{2}{*}{0.243} \\
\hline Christian & $\mathbf{3}$ & 5.8 & $\mathbf{0}$ & $\mathbf{0}$ & & \\
\hline \multicolumn{7}{|l|}{ Educational level } \\
\hline Primary & 5 & 9.6 & 10 & 19.2 & \multirow{3}{*}{2.34} & \multirow{3}{*}{0.310} \\
\hline Secondary & 16 & 30.8 & 17 & 32.7 & & \\
\hline University & 31 & 59.6 & 25 & 48.1 & & \\
\hline \multicolumn{7}{|l|}{ Occupation } \\
\hline Housewife & 40 & 76.9 & 47 & 90.4 & \multirow{2}{*}{$3.446^{*}$} & \multirow{2}{*}{0.110} \\
\hline Employee & 12 & 23.1 & 5 & 9.6 & & \\
\hline
\end{tabular}

* Fisher's Exact Test $\quad \mathrm{t}=$ Independent Samples Test 
Table 2. Mean of outcome expectancy and self-efficacy expectancy scores obtained by the study groups at pretest, posttest, and follow-up assessment

\begin{tabular}{|c|c|c|c|c|c|c|}
\hline \multirow{2}{*}{$\begin{array}{c}\text { Childbirth } \\
\text { Self-Efficacy Inventory (CBSEI) } \\
\text { Subscales } \\
\end{array}$} & \multicolumn{2}{|c|}{$\begin{array}{c}\text { Antenatal Education } \\
\text { Group }(\mathbf{n}=\mathbf{5 2}) \\
\end{array}$} & \multicolumn{2}{|c|}{$\begin{array}{c}\text { Control Group } \\
(\mathrm{n}=52)\end{array}$} & \multicolumn{2}{|c|}{ Test of Significance } \\
\hline & Mean & SD & Mean & SD & t-test & p-value \\
\hline \multicolumn{7}{|c|}{ Pretest } \\
\hline Outcome Expectancy & 137.52 & 6.26 & 136.79 & 6.11 & 0.602 & 0.548 \\
\hline Self-Efficacy Expectancy & 148.23 & 7.45 & 148.21 & 7.45 & 0.013 & 0.990 \\
\hline \multicolumn{7}{|c|}{ Posttest } \\
\hline Outcome Expectancy & 239.17 & 8.56 & 133.31 & 20.62 & 34.191 & $<0.001$ \\
\hline Self-Efficacy Expectancy & 242.33 & 8.06 & 152.06 & 20.91 & 29.052 & $<0.001$ \\
\hline \multicolumn{7}{|c|}{ Follow Up Assessment } \\
\hline Outcome Expectancy & 236.37 & 6.57 & 137.92 & 25.82 & 26.647 & $<0.001$ \\
\hline Self-Efficacy Expectancy & 240.46 & 10.25 & 152.59 & 21.17 & 26.935 & $<0.001$ \\
\hline
\end{tabular}

$\mathrm{t}=$ Independent Samples Test

Table 3. Mean score of labour pain of the study groups at $1^{\text {st }}$ and $2^{\text {nd }}$ stages of labour

\begin{tabular}{|c|c|c|c|c|c|c|}
\hline \multirow[t]{2}{*}{ Labour Pain Score } & \multicolumn{2}{|c|}{$\begin{array}{c}\text { Antenatal Education } \\
\text { Group }(\mathrm{n}=\mathbf{5 2})\end{array}$} & \multicolumn{2}{|c|}{$\begin{array}{c}\text { Control Group } \\
(n=52)\end{array}$} & \multicolumn{2}{|c|}{$\begin{array}{c}\text { Test of } \\
\text { Significance } \\
\end{array}$} \\
\hline & Mean & SD & Mean & SD & t-test & p-value \\
\hline \multicolumn{7}{|l|}{$1^{\text {st }}$ Stage of Labour } \\
\hline & 5.08 & 0.68 & 7.40 & 0.5 & 19.913 & $<0.001$ \\
\hline \multicolumn{7}{|l|}{$2^{\text {nd }}$ Stage of Labour } \\
\hline & 6.52 & 0.5 & 8.56 & 0.7 & 16.247 & $<0.001$ \\
\hline
\end{tabular}

$\mathrm{t}=$ Independent Samples Test

Table 4. Correlations between CBSEI subscales (outcome and self-efficacy expectancies) and labour pain score in the antenatal education group at pretest, posttest, and follow-up assessment

\begin{tabular}{|c|c|c|c|c|}
\hline \multirow{3}{*}{ The CBSEI Subscales } & \multicolumn{4}{|c|}{ Labour Pain Score } \\
\hline & \multicolumn{2}{|c|}{$1^{\text {st }}$ Stage of Labour } & \multicolumn{2}{|c|}{$2^{\text {nd }}$ Stage of Labour } \\
\hline & $\mathbf{r}$ & $\mathbf{p}$ & $\mathbf{r}$ & p \\
\hline \multicolumn{5}{|c|}{ Before Applying Antenatal Education Classes (Pretest) } \\
\hline Outcome Expectancy & -0.014 & 0.921 & -0.149 & 0.291 \\
\hline Self-Efficacy Expectancy & $\mathbf{0 . 0 5 0}$ & 0.722 & -0.105 & 0.457 \\
\hline \multicolumn{5}{|c|}{ After Applying Antenatal Education Classes (Posttest) } \\
\hline Outcome Expectancy & -0.473 & $<0.001$ & -0.466 & $<0.001$ \\
\hline Self-Efficacy Expectancy & -0.333 & 0.016 & -0.313 & 0.024 \\
\hline \multicolumn{5}{|c|}{ Follow Up Assessment } \\
\hline Outcome Expectancy & -0.440 & 0.001 & -0.283 & 0.042 \\
\hline Self-Efficacy Expectancy & -0.373 & 0.006 & -0.317 & $\mathbf{0 . 0 2 2}$ \\
\hline
\end{tabular}

$r=$ Pearson Correlation

Table 5. Correlations between CBSEI subscales (outcome and self-efficacy expectancies) and labour pain score in the control group at pretest, posttest, and follow-up assessment

\begin{tabular}{|c|c|c|c|c|}
\hline \multirow{3}{*}{ The CBSEI Subscales } & \multicolumn{4}{|c|}{ Labour Pain Score } \\
\hline & \multicolumn{2}{|c|}{$1^{\text {st }}$ Stage of Labour } & \multicolumn{2}{|c|}{$2^{\text {nd }}$ Stage of Labour } \\
\hline & $\mathbf{r}$ & $\mathbf{p}$ & $\mathbf{r}$ & $\mathbf{p}$ \\
\hline \multicolumn{5}{|c|}{ Pretest } \\
\hline Outcome Expectancy & 0.145 & 0.304 & 0.115 & 0.416 \\
\hline Self-Efficacy Expectancy & 0.008 & 0.954 & 0.003 & 0.980 \\
\hline \multicolumn{5}{|c|}{ Posttest } \\
\hline Outcome Expectancy & -0.250 & 0.73 & -0.135 & 0.339 \\
\hline Self-Efficacy Expectancy & 0.242 & 0.084 & 0.142 & 0.316 \\
\hline \multicolumn{5}{|c|}{ Follow Up Assessment } \\
\hline Outcome Expectancy & -0.112 & 0.427 & -0.034 & 0.812 \\
\hline Self-Efficacy Expectancy & 0.244 & 0.081 & 0.137 & 0.332 \\
\hline
\end{tabular}

$r=$ Pearson Correlation 


\section{Discussion}

This study aimed to test the antenatal education on childbirth self-efficacy for Egyptian primiparous women. The aim of study and hypotheses were achieved through the study findings which highlighted improving in the childbirth self-efficacy for Egyptian primiparous women and their confidence that they could fruitfully accomplished coping behaviours during childbirth process after attending the antenatal education classes. A systematic review conducted by Brixval et al., (2014) reported that there are many researches examined the effectiveness of antenatal education on childbirth outcomes worldwide, but till now, most such researches carried out in Western countries [6]. Al-Ateeq et al., (2013) they studied the perceptions of antenatal education among Saudi women, they concluded insufficient information provided to pregnant women during ANC [28]. Additionally, a qualitative study in three Arab countries conducted by Khasholian et al., (2015) found absence of antenatal preparatory classes and there were many barriers for implementing labour companionship in Lebanon, Syria and Egypt [29]. Regarding socio-demographic characteristics of both studied groups. The study revealed that no significant differences among the antenatal education and control groups regarding age, educational level, place of residence, and occupation. This may be due to homogenous random distribution of participants to antenatal education and control groups would assure that groups are equal and decreasing the influence of groups differences that could impact on outcome results. This study finding is supported by Howharn (2008) who studied the effects of childbirth education on self-efficacy of primiparous women in Thailand. She recommended random assignment should be planned in the future nursing research to assure the experimental and control groups are equivalent and minimizing effects of group differences that might affect outcome measures [30]. Regarding the mean of outcome expectancy and self-efficacy expectancy scores obtained by the study groups at pretest, posttest, and follow-up assessment. The study highlighted that, at pretest there were no significant differences between the antenatal education and control groups regarding the mean score of both outcome and self efficacy expectancies. But there were highly significant differences between the two groups at posttest and during follow-up assessment. Clearly, the mean score of both expectancies were higher in the antenatal education group. This may be due to women who received the session of antenatal education classes learns how to develop self- reliance during labour, had practical skills that increased their self-confidence and decreased their fear during whole period of childbirth process. Also, learning the techniques of coping during labour pain can lead to the development of women's self-confidence and childbirth self-efficacy. This is in consistent with Serçekuş \& Başkale (2016) they studied the effects of prenatal education on childbirth self-efficacy in Turkey, they found no significant differences between the two groups at pre education scores of outcome and self-efficacy expectancies, however a significant differences was found between the two groups at post education scores [8]. Similarly, Taheri et al., (2014) they studied effect of antenatal education on selecting delivery method in Iran, they also found a significant difference between the two groups regarding both expectancies after but not before intervention [31]. In the present study NRS was utilized to assess labour pain between the two groups at the first and second stage of labour. Regarding labour pain score of both studied groups at the first stage of labour. The study illustrated that women in the antenatal education group had significantly lower level of pain score than women in the control group. This may be due to that women who were in the education group being well informed and recognized the source of pain which lead to positive attitude towards normal labour as less fear. Additionally, women learned how to implement coping and practical relaxation techniques during labour pain. This is in agreement with Hosseininasab \& Taghavi (2010) they studied the effect of antenatal education on childbirth pain and anxiety in Iran, they found less level of labour pain in the experimental group [32]. Also, Ip et al., (2009) they studied the effects of antenatal educational program on women's coping with childbirth process in China, they found that experimental group demonstrated lower pain level in the first and middle phases of the first stage of labour [33]. Additionally, Firouzbakht et al., (2015) they also found labour pain intensity in the transitional phase of cervical dilatation $(8-10 \mathrm{~cm})$ was significantly less in educated group [34]. Regarding labour pain score of both studied groups at the second stage of labour. The study revealed again that women who were in the antenatal education group had significantly lower level of pain score than group who were received only routine care. This is not in agreement with Firouzbakht et al., (2014) they studied the effect of antenatal education on labour pain of Iranian women, they found no significant difference between both groups at the second stage of childbirth [35]. This may be due to difference in pain threshold and tolerance among studied groups. Regarding correlations between the CBSEI subscales (outcome and self-efficacy expectancies) and labour pain in the antenatal education group at pretest, posttest, and follow-up assessment. The study highlighted that, at pretest there were no significant correlation between the CBSEI subscales and labour pain. However, at posttest and during the follow-up there were significant negative correlation between CBSEI subscales and labour pain score during both the first and second stages. This indicates that labour pain decrease with increasing the childbirth self-efficacy and vice versa. This is in agreement with El-Homosy (2012) who studied the effect of childbirth education on self-efficacy among primiparous women in Menoufiya Governorate, Egypt, she also found significant correlation between CBSEI subscales and labour pain in the intervention group [36]. Similarly, a longitudinal study conducted by 
Berentson-Shaw et al., (2009) they studied the predictive role of childbirth self-efficacy beliefs on birthing experiences among primiparous in New Zealand, they concluded that stronger beliefs of childbirth self-efficacy predicted decreased pain and distress during childbirth process [37]. Regarding correlations between the CBSEI subscales (outcome and self-efficacy expectancies) and labour pain in the control group at pretest, posttest, and follow-up assessment. The study illustrated no significant correlation between the CBSEI subscales and labour pain at pretest, posttest, and follow-up assessment. This indicates that labour pain increase with decreasing the childbirth self-efficacy and vice versa. This is in consistent with El-Homosy (2012) who also found no significant correlation between CBSEI subscales and labour pain in group who were received only usual care [36].

\section{Conclusion}

Based on the study findings, it is concluded that, antenatal education classes give an actual chance for helping primiparous women learn how effectively improving childbirth self-efficacy. The study results highlighted the effect of antenatal education classes in increasing women's childbirth self-efficacy and reducing women's pain in the first and second stages of childbirth. Also, the study findings clarified that, labour pain decrease with increasing the childbirth self-efficacy inventory and vice versa. Finally all presented study findings are particularly essential for developing countries like Egypt, where antenatal education are not applied as a component of standard antenatal care.

\section{Recommendations}

Based on the study findings, the study is recommending the following:-

- Designing and applying antenatal education classes as an essential component of standard antenatal care at different affiliated Egyptian public hospitals.

- Designing and applying childbirth preparation classes in the third trimester of pregnancy particularly for primigravidas to promote their self-control during labour that lead to a more satisfactory birthing experience.

- Designing comprehensive updated booklet of childbirth preparation suited and tailored to the culture of the Egyptian women and distributed through private and different affiliated Egyptian antenatal clinics.

- Further studies are recommended to investigate the effect of antenatal education classes on women's selfefficacy for selecting delivery method (normal or caesarean delivery).

- Further studies are recommended to explore the perceptions and attitudes of healthcare providers toward applying antenatal educational classes.

- Designing and implementing antenatal educational training programs into maternity and midwifery nursing undergraduate curriculum.

\section{References}

[1] S.S. Ricci, Essentials of Maternity, Newborn, and Women's Health Nursing. ( $3^{\text {rd }}$ Ed). (China: Wolters Kluwer Health, Lippincott Williams \& Wilkins 2013) 380-381,433.

[2] J. Oats and S. Abraham, Llewellyn-Jones Fundamentals of Obstetrics and Gynaecology. (10 ${ }^{\text {th }}$ Ed). (China: Elsevier 2017) 40, 54.

[3] T.F. Baskett, A.A. Calder, and S. Arulkumaran, Munro Kerr's Operative Obstetrics. (12 ${ }^{\text {th }}$ Ed). (China: Saunders Elsevier 2014) 31,236-237.

[4] T.L. King, M.C. Brucker, J.M. Kriebs, J.O. Fahey, C.L. Gegor, and H. Varney, Varney's Midwifery. (5 ${ }^{\text {th }}$ Ed). (United State of America: Jones and Bartlett Publishers 2015) 682,795,813.

[5] I. Peate, K. Wild, and M. Nair, Nursing Practice Knowledge and Care. (UK: Wiley-Blackwell 2014) $259,263$.

[6] C.S. Brixval, S.F. Axelsen, S.K. Andersen, P. Due, and V. Koushede, The effect of antenatal education in small classes on obstetric and psycho-social outcomes: a systematic review and meta-analysis protocol, Systematic Review, 13(3), $2014,12$.

[7] G.G. İsbir, F. İnci, H. Önal, and P.D. Y1ldı, The effects of antenatal education on fear of childbirth, maternal self-efficacy and posttraumatic stress disorder (PTSD) symptoms following childbirth: an experimental study, Applied Nursing Research. 32, 2016, 227-232.

[8] S. Ferguson, D. Davis, and J. Browne, Does antenatal education affect labour and birth? A structured review of the literature, Women and Birth 26 (1), 2013, e5 - e8.

[9] A.J. Gagnon, and J. Sandall, Individual or group antenatal education for childbirth or parenthood, or both (Review), Cochrane Database of Systematic Reviews 2011, Issue 3. Art. No. CD002869. DOI: 10.1002/14651858.CD002869.pub2.

[10] P. Serçekuş, and H. Başkale, Effects of antenatal education on fear of childbirth, maternal self-efficacy and parental attachment, Midwifery. 34, 2016, 166-172.

[11] D.L. Lowdermilk, S.E. Perry, and K. Cashion, Maternity Nursing. ( $8^{\text {th }}$ Ed). (United States of America: Mosby Elsevier 2014) 230232,278 ,

[12] J. Toohill, J. Fenwick, J. Gamble, and Creedy D.K., Prevalence of childbirth fear in an Australian sample of pregnant women. BMC Pregnancy and Childbirth, 14, 2014, 275.

[13] J. Fenwick, J. Toohill, D.K. Creedy, J. Smith, and J. Gamble, Sources, responses and moderators of childbirth fear in Australian women: A qualitative investigation. Midwifery 31(1), 2015, 239-246.

[14] A. Kizılırmak and M. Baser, The effect of education given to primigravida women on fear of childbirth, Applied Nursing Research 29, 2016, 19-24.

[15] S. Downe, K. Finlayson, Ö. Tuncalp, and A.M. Gülmezoglu, What matters to women: a systematic scoping review to identify the processes and outcomes of antenatal care provision that are important to healthy pregnant women. BJOG: An Inernational Journal of Obstetrics \& Gynaecology . 123 (4), 2015, 529-539 
[16] T. Dowswell, G. Carroli, L. Duley, S. Gates, A.M. Gülmezoglu, D. Khan-Neelofur, and G. Piaggio, Alternative versus standard packages of antenatal care for low-risk pregnancy (Review). Cochrane Database of Systematic Reviews 2015, Issue 7. Art. No. CD000934. DOI: 10.1002/14651858. CD000934.pub3, 2015.

[17] Egyptian Initiative for personal rights, The Right to Reproductive Health Services and Information. Articles $10,12,14$ (2) b and 16 (1), 2010 .

[18] A. El-Nemer, Effect of Childbirth Counseling on Pregnant Women Requested for Cesarean Delivery, IOSR Journal of Nursing and Health Science (IOSR-JNHS), 4 (4), 2015, 24:29.

[19] MOHP, Egypt Demographic and Health Survey 2015. Retrieved from.https://dhsprogram.com/pubs/pdf/FR302/FR302.pdf.

[20] S.N. Abd El-Aziz, S.E. Mansour, and N.F. Hassan, Factors associated with fear of childbirth: It's effect on women's preference for elective cesarean section. Journal of Nursing Education and Practice, 7 (1), 2016, 133- 146.

[21] M.A. Miquelutti, J.G. Cecatti, and M.Y. Makuch, Antenatal education and the birthing experience of Brazilian women: a qualitative study.BMCPregnancyandChildbirth,13:171,2013,Retrievedfrom.http://bmcpregnancychildbirth.biomedcentral.com/articles/10.1186 /1471-2393-13-171. On 2017.

[22] N.K. Lowe, Maternal Confidence for Labor: Development of the Childbirth Self Efficacy Inventory. Research in Nursing \& Health, 16 (2), 1993, 141-149.

[23] H. Breivik, P.C. Borchgrevink, S.M. Allen, L.A. Rosseland, L Romundstad., E.K. Breivik Hals, G. Kvarstein, and A. Stubhaug, Assessment of pain. British Journal of Anaesthesia, 101 (1), 2008, 17-24.

[24] K.R. Jones, C.P. Vojir, E. Hutt, and R. Fink, Determining mild, moderate, and severe pain equivalency across pain intensity tools in nursing home residents. Journal of Rehabilitation Research and Development, 44 (2), 2007, 305-314.

[25] G. Dick-Read, Natural childbirth. (London: Heinemann 1993).

[26] F. Lamaze, Painless childbirth: Psychoprophylactic method. (London: Burke 1958)

[27] M. Mongan, HypnoBirthing: The Mongan Method, A natural approach to safer, easier, more comfortable birthing. (4 ${ }^{\text {th }}$ Ed). (United State of America, Health Communication 2015). 21.

[28] M.A. Al-Ateeq, A.A. Al-Rusaiess, and A.A. Al-Dughaither, Perceptions and effects of antenatal education. Saudi Medical Journal 34 (12), 2013, $1287-1293$.

[29] T.K. Khasholian, A. El-Nemer, and H. Bashour, Perceptions about labor companionship at public teaching hospitals in three Arab countries. International Journal of Gynecology and Obstetrics 129 (3), 2015, 223-226.

[30] C. Howharn, Effects of Childbirth Preparation Classes on Self-Efficacy in Coping with Labor Pain in Thai Primiparas, doctoral diss., Faculty of the Graduate School, University of Texas, Austin, 2008.

[31] Z. Taheri, M.A. Mazaheri, M. Khorsandi, A. Hassanzadeh and M. Amiri, Effect of Educational Intervention on Self efficacy for Choosing Delivery Method among Pregnant Women in 2013. International Journal of Preventive Medicine, 5 (10), 2014, 12471254.

[32] D. Hosseininasab, and S. Taghavi, The Effectiveness of Prenatal Education in Decreasing the Childbirth Pain and Anxiety. Medical Journal of Tabriz University of Medical Sciences \& Health Services, 31(4), 2010, 24-30.

[33] W.Y. Ip, C.S. Tang, and W.B. Goggins, An educational intervention to improve women's ability to cope with childbirth, Journal of Clinical Nursing 18, 2009, 2125-2135.

[34] M. Firouzbakht, M. Nikpour, S. Khefri, B. Jamali, F. Kazeminavaee, and M. Didehdar, The Effectiveness of Prenatal Intervention on Pain and Anxiety during the Process of Childbirth-Northern Iran: Clinical Trial Study. Annals of Medical and Health Sciences Research 5(5), 2015, 348-352.

[35] M. Firouzbakht, M. Nikpour, H. Salmalian, F.M. Ledari, and S. Khafri, The Effect of Perinatal Education on Iranian Mothers' Stress and Labor Pain. Global Journal of Health Science. 6 (1), 2014, 61-68.

[36] S.M. El-Homosy, Effect of Childbirth Preparation on Self Efficacy in Coping with Labor Pain in Primiparas, doctoral diss., Faculty of Nursing, Menoufiya University, Egypt, 2012.

[37] J. Berentson-Shaw, K.M. Scott, and P.E. Jose, Do self-efficacy beliefs predict the primiparous labour and birth experience? A longitudinal study. Journal of Reproductive and Infant Psychology 27 (4), 2009, 357-373.

\section{3-Week antenatal class series outline. (Table 5)}

\begin{tabular}{|c|c|c|}
\hline Weeks & Content & Objectives \\
\hline $\begin{array}{l}\text { The First } \\
\text { Class } \\
\left(1^{\text {st }} \text { Week }\right)\end{array}$ & $\begin{array}{l}\text { Overview of } \\
\text { Labour and } \\
\text { Delivery }\end{array}$ & $\begin{array}{l}\text { 1. Welcome \& develop rapport among group participants } \\
\text { 2. Explain the objectives of antenatal education classes } \\
\text { 3. Encourage participants to express their feeling and sharing thoughts about } \\
\text { childbirth process. } \\
\text { 4. Introduction to pretest questionnaires (Interview - CBSEI) } \\
\text { 5. Anatomy and physiology of female genital organs } \\
\text { 6. Premonitory signs of labour } \\
\text { 7. True and false labour pain } \\
\text { 8. What to bring to the hospital } \\
\text { 9. Overview of stages and phases of labour }\end{array}$ \\
\hline $\begin{array}{l}\text { The Second } \\
\text { Class } \\
\left(2^{\text {nd }} \text { Week }\right)\end{array}$ & $\begin{array}{l}\text { Coping with } \\
\text { Labour Pain }\end{array}$ & $\begin{array}{l}\text { 1. Review content from class one } \\
\text { 2. Nature of labour pain } \\
\text { 3. Non-pharmacological coping measures with labour pain } \\
\text { 4. Medications used in labour } \\
\end{array}$ \\
\hline $\begin{array}{l}\text { The Third } \\
\text { Class } \\
\left(3^{\text {rd }} \text { Week }\right)\end{array}$ & $\begin{array}{l}\text { Delivery and } \\
\text { Postpartum }\end{array}$ & $\begin{array}{l}\text { 1) Brief review the content of class } 1-2 \text { and ask for the question and discuss } \\
\text { the answer if they have } \\
\text { 2) Delivery variations (Episiotomy and C-section) } \\
\text { 3) Immediate postpartum care in hospital } \\
\text { 4) Newborn care } \\
\text { 5) Posttest (CBSEI) }\end{array}$ \\
\hline
\end{tabular}




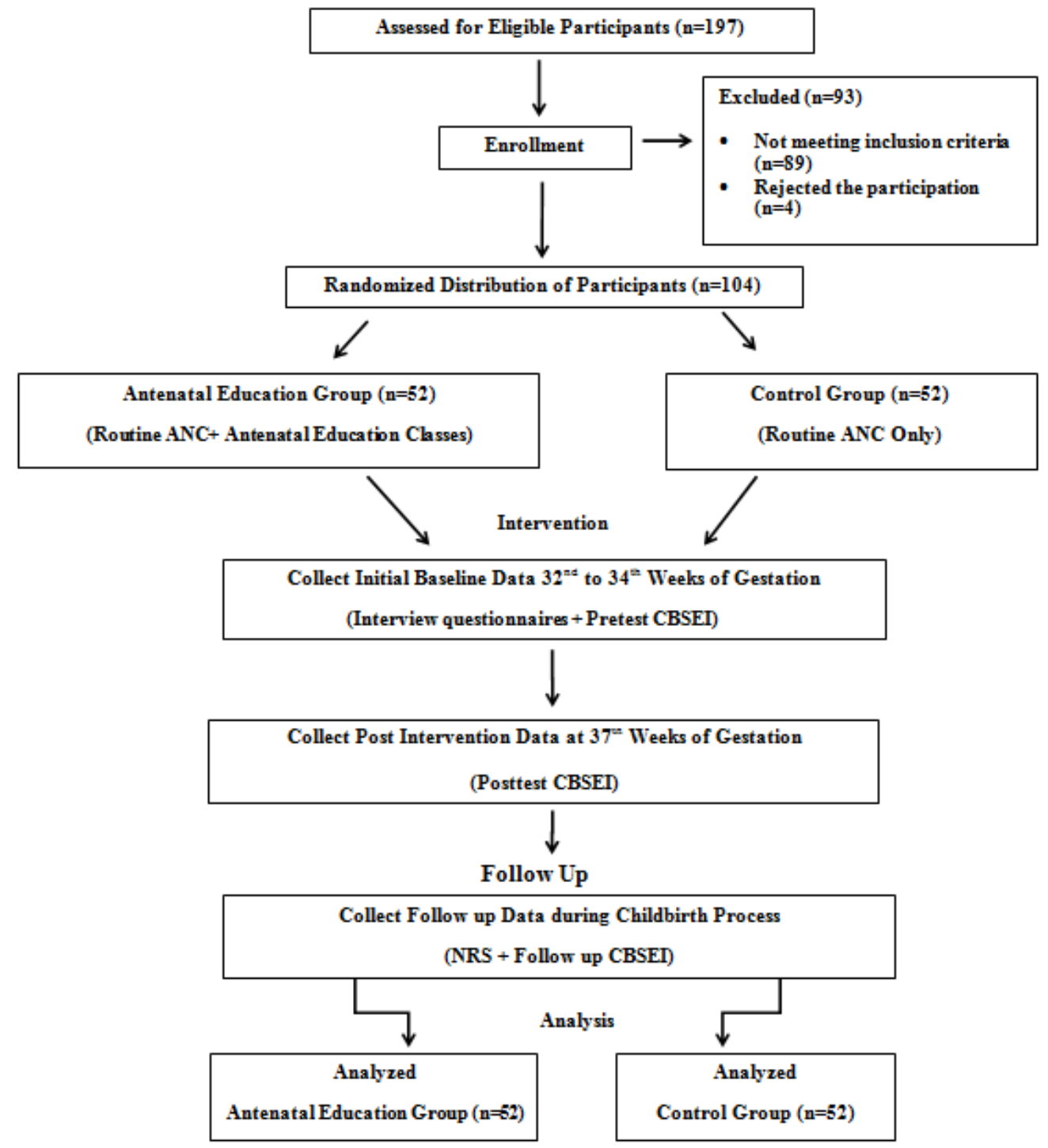

Fig. 1.The Flow Chart of the Study Phase

Rania El-Kurdy . " Antenatal Education on Childbirth Self-Efficacy for Egyptian Primiparous Women: A Randomized Control Trial ." IOSR Journal of Nursing and Health Science (IOSR-JNHS) 6.4 (2017): 15-23. 